\title{
A Note on Aphasia in Bilingual Patients: Pitres' and Ribot's Laws
}

\author{
J.M.S. Pearce \\ Emeritus Consultant Neurologist, Department of Neurology, Hull Royal Infirmary, Hull, UK
}

\section{Key Words}

Bilingual patients · Aphasia - Lexicons · Pitres' law · Ribot's law

\begin{abstract}
Johann Gesner in 1770 probably provided the first description of dissociation in reading ability in different languages in a bilingual patient, who after brain damage was able to read Latin but not German. Clinical studies have since shown that bilingual 'aphasics' do not necessarily manifest the same language disorders with the same degree of severity in both languages. Superficially, different case findings indicate instances of shared and divergent representation of components of language in the bilingual brain. This paper considers a selection of many empirical studies, which have failed to reconcile the parallel recovery of language in many reported bilingual aphasiacs and the differential recovery in others. It reviews Pitres' rule (recovery of the most used acquired language) and Ribot's law (recovery of the native language) that are important concepts during recovery and rehabilitation of bilingual aphasiacs.
\end{abstract}

Copyright $(2005$ S. Karger AG, Basel

The cortical representation of both a native and a second language has long been an object of uncertainty. We do not yet know whether they are associated with the same or distinct cortical areas [1]. Bilingualism is now commonplace. It is the use of two (or more) languages in everyday life, but it is not knowing two or more languages equally well (as most laypersons think) [2]. Bilinguals have language networks, which are independent in that they allow a bilingual to speak just one language, but they are interconnected in the sense that the monolingual speech of bilinguals often shows the intrusion or interference of the other language, and when bilinguals talk to other bilinguals, they can readily code-switch and borrow words.

This paper pretends no neurolinguistic expertise ${ }^{1}$, but seeks to draw attention to fascinating phenomena, which can perplex the clinician.

\section{Historical Note}

Johann Gesner (1738-1801) [3] in 1770 probably provided the first known description of dissociation in reading in different languages in a bilingual abbot, who after brain damage was able to read Latin but not German. In 1843, Jacques Lordat (1773-1870) [4], professor of anatomy and physiology in Montpellier, reported the case of a bilingual (Occitan ${ }^{2}$ and French) priest, a native of Languedoc in Southern France. This man was apparently affected by a massive selective deficit in French, whereas his Occitan was unaffected. Lordat also gave the first autobiographical account of 'differential dyslexia', say-

\footnotetext{
1 The terminology of linguistics is complex. Therefore, for a useful glossary, see: http://www.smithsrisca.demon.co.uk/psycholinguistics-glossary.html.

Dialect formerly spoken in Provence.
}

\section{KARGER}

Fax +4161306 1234 E-Mail karger@karger.ch www.karger.com (c) 2005 S. Karger AG, Basel 0014-3022/05/0543-0127\$22.00/0

Accessible online at:

www.karger.com/ene
J.M.S. Pearce

304 Beverley Road

Anlaby, East Yorks HU10 7BG (UK) 
ing that after he himself had suffered a stroke he was unable to speak or read properly because:

'The thought was quite ready, but the sounds which should have confided it to the intermediary were no longer at my disposal ... I said to myself [cu moi même]: So it is true that I can no longer speak. ... Syntax had disappeared. The alphabet alone was left to me, but the function of the letters for the formation of words was a study yet to be made. I had to spell out slowly most of the words' [4].

Clinical studies have shown that bilingual 'aphasics'3 do not necessarily manifest the same disorders of language with the same degree of severity in both languages. The pattern varies with time; therefore, assessment of both monolingual and bilingual aphasics should take into account [9] the acute phase, the 'lesion phase' which lasts for several weeks and the late phase, beginning a few months after onset.

Contradictory findings indicate both a shared and a divergent representation of components of language in the bilingual brain.

\section{Pitres' Law and Ribot's Law}

How the polyglot or bilingual aphasiac recovers various fractions and patterns of language has caused controversy. Many studies have illustrated striking individual cases, culminating in Pitres' law (1895) - recovery of the most familiar language. This stated:

'In acquired aphasia with a multilingual patient, recovery comes first and most completely in the language most used just before the injury, whether or not it is the patient's mother tongue' [5].

By contrast, Ribot's law - recovery of the native language - stated:

'In a multilingual patient with aphasia, recovery comes first in the person's mother tongue ...' [6].

Ribot's law [7], however, was principally applied to the relative sparing of older memories in retrograde amnesia. It has been found to be true only in patients who are not truly fluent in the subsequently acquired languages. On clinical examination, public or personal events occurring in close proximity to the onset of amnesia may seem to be disproportionately impaired and older memories may seem to be more deeply entrenched and consequently spared.

\footnotetext{
3 Strictly speaking, most are dysphasics.
}

\section{Patterns of Recovery in Bilingual Aphasiacs}

Pitres [5] proposed that the recovery pattern could occur only if the lesion had not destroyed language centres, but had temporarily inhibited them. He stated the patient generally recovered the most familiar language because the neural elements subserving it were more firmly associated. But no clear evidence supports a rule applicable to all cases.

Paradis [8] identified six recovery patterns. Languages can be affected in parallel, differentially or selectively.

1 Parallel recovery occurs when both languages are impaired and restored at the same rate.

2 Differential recovery occurs when languages recover differentially relative to their premorbid levels.

3 Selective recovery occurs when one language is not recovered. In blended recovery, patients inappropriately mix their languages. Nearly $30 \%$ of the cases show a selective pattern of recovery (the patient did not regain one or more of his languages). Paradis cites some of the cases reported by Pitres (1895) [5]. One patient of Pitres recovered French and Spanish, but lost the ability even to comprehend Italian. Another patient regained some of his proficiency in French but not in German, English, Spanish or Arabic, all of which he spoke fluently before the injury.

4 Antagonistic type of recovery pattern. One language recovers to a certain extent first and it starts regressing when the other language begins to recover. The antagonistic pattern of recovery is seen to be the least common. By contrast, in selective aphasia, there is aphasia in one language without impairment evident in the other.

5 Rates of recovery vary. Two languages may eventually recover but recovery of the second language may only begin after the first has recovered, which is called successive recovery of one language after the other.

6 Less often, there are mixed patterns or mutual interference between the languages seen in the process of recovery.

\section{Incidence}

The approximate incidence of the recovery pattern has been studied in 20 bilingual Friulian ${ }^{4}$-Italian aphasics [9]. Thirteen patients (65\%) showed a similar impairment in both languages (parallel recovery), 4 patients $(20 \%)$

4 The region between the Alps and the Adriatic Sea. 
showed a greater impairment of the secondary language (L2), while 3 patients (15\%) showed a greater impairment of the first acquired language (L1). The type of aphasic syndrome, the type of lesion (e.g. cerebral tumour, infarction or haemorrhage) or the site of the lesion (cortical vs. subcortical, frontal lobe vs. temporal lobe) did not seem to be directly responsible for parallel language recovery versus differential recovery.

Does the age (early or late) of acquiring a language affect the areas of cortex activated whilst using that language? And, in acquired aphasia, is there a differential pattern? The representation of grammatical aspects of languages seems to be different between the two languages if L2 is acquired after the age of 7 , with automatic processes and correctness being lower than those of the native language. These results imply a greater representation of the two lexicons in the memory systems, whereas word form and syntax may be organized in different systems according to the acquisition versus learning modality [10]. However, there is evidence that the degree of proficiency in acquisition of a language is critical to brain activation patterns (e.g. for cerebral blood flow) [11] in language tasks. There appears to be a common cortical representation for $\mathrm{L} 1$ and L2 when the proficiency in both languages is comparable.

Symptoms peculiar to bilingual aphasia may be evident as pathological mixing and switching and as disorders of translation. Neurophysiologic and neuroimaging studies show a similar cerebral representation of L1 and L2 lexicons both in early and late bilinguals.

Many hypotheses [12] are advanced to account for disparate recovery, but none of them provides adequate explanations. The study of bilingual aphasics who show parallel impairment of both languages confirms that grammatical disorders in aphasia depend on the language structure, not just vocabulary. Therefore, in agrammatic patients who know two languages, grammatical errors are expected to be similar in both languages and will differ only at points where the two languages differ.

\section{Speculative Mechanisms of Recovery in Bilingual Aphasiacs}

A differential pattern may arise because preference for one language over the other provides better functional neural recovery referred to as Hebbian ${ }^{5}$ learning [13]. The

\footnotetext{
5 In Hebbian learning, two neurons or neuronal groups or circuits are be-
lieved to reconnect if they are activated at the same time. Spontaneous recovery

5 In Hebbian learning, two neurons or neuronal groups or circuits are be-
lieved to reconnect if they are activated at the same time. Spontaneous recovery can arise in the case of well-connected networks with small lesions by random activation of one of the groups.
}

Aphasia in Bilingual Patients progressive use of a single language may functionally enhance its network and progressively isolate it from the alternative language. Or, damage to the mechanism for choice or selection of the language, or a disconnection of the link connecting the meanings of words and the coding of language may cause selective improvement.

Another possibility is that the control of one language is impaired if its lexicosemantic system (the known meanings of the words, but not the words themselves) is more impaired than that of the other language; there is access to meaning but an inability to select lexical concepts in the nonrecovered language causing reduced control.

Antagonistic recovery may be construed as a special case of selective recovery. Why should the recovery of one language be impaired, whilst a second language improves? Initial language use is probabilistically determined. An initially less dominant language schema becomes more dominant (via Hebbian learning), inhibiting the use of the other language. As in the case of selective recovery, we can assess what information is available for the less recovered language by tests designed by neurolinguists to examine access to word forms.

\section{Anatomical and Physiological Studies}

In an attempt to gain a better anatomical understanding of how multiple languages are represented in the human brain, Roux and Trémoulet [14] studied 12 bilingual patients who underwent surgery for brain tumours, during which they mapped cortical language sites by using electrostimulation. Strict overlapping of language areas (for all language tasks) was found in 5 patients, whereas the remaining 7 had at least one area that was language specific and sometimes task specific. Specific areas for a particular language, that is differential impairment, were found for anomia in 8 sites (50\%) but also in $6(20 \%)$ of the reading or counting sites (speech arrest), either in frontal ( 3 patients) or in temporoparietal (4 patients) regions. Among the 4 early bilingual patients tested (languages acquired before the age of 7 years), 3 had 'language-specific cortical areas'. Interestingly, 6 patients in this series who had a differential discrepancy between the two languages did not have more cortical areas devoted to the less proficient language.

Lucas et al. [15] also found distinct language-specific sites as well as shared sites that supported both L1 and L2. The L1 and L2 representations were similar in total cortical extent but significantly different in anatomical distribution. The L2-specific sites were exclusively in the 
posterior temporal and parietal regions, whereas the L1 and shared sites could be found throughout the mapped regions. Bilinguals possessed seven peri-Sylvian language zones, in which L2 sites were significantly underrepresented when compared with the distribution of language sites in monolinguals. L1 and L2 sites were functionally distinct.

In a report of a bilingual aphasiac due to subcortical lesions, the deficit in mother tongue production was observed in spontaneous speech and in cross-language translation tasks, where an asymmetrical paradoxical performance was shown. The patient had more difficulties when translating into her mother tongue (Venetian) than into her second language (Italian). This pattern was similar in written and oral translation tasks, thus ruling out the possibility that the deficit simply reflects differences between written and oral language codes.

This case suggests a higher degree of 'automatization' of the first language than of the second one [16].

\section{Neuroimaging}

In support of an anatomical overlap between the first (L1) and second (L2) languages, Chee et al. [17] showed in an fMRI study that during word stem completion among Mandarin-English bilinguals, the task resulted in similar activation of the left inferior frontal gyrus, the supplementary motor area and the occipital and parietal areas bilaterally, during the task in both languages. It is remarkable that two such divergent languages overlap in terms of lexical representation, for these results argue for shared lexicons between the first and second languages.

The neural systems underlying translation and language switching were investigated using PET in 6 subjects whose native language (L1) was German and who became fluent in English (L2) after about the age of 9. They were scanned whilst either translating or reading visually presented words in German (L1), English (L2) or alternating L1/L2. The results revealed contrasting patterns of activation for translation and switching, suggesting at least partially independent mechanisms. Translation, but not switching languages, increased activity in the anterior cingulate and subcortical structures whilst decreasing activation in several other temporal and parietal language areas. Translation also increased activation in regions associated with articulation, arguably because the reading response to the stimulus must be inhibited whilst a response in a different language is activated. In contrast, switching the input language resulted in activation of
Broca's area and the supramarginal gyri, areas associated with phonological recoding [18]. The authors suggest that at least certain types of bilingual aphasia may reflect deficits in controlling relatively intact lexicosemantic systems.

\section{Pitres and Ribot}

These and other recent results [9] confirm the three possible patterns of recovery described in Pitres' book [5] (the first on bilingual aphasia ever published), i.e. parallel, selective and successive recovery. In some cases, aphasia affects only one language known by the patient. In his study of 1895, Pitres [5] emphasised that the dissociation of the languages affected by aphasia was not exceptional. He described 7 clinical cases of patients exhibiting differential recovery of the two languages they spoke. He suggested that patients tended to recover the language that was most familiar to them before the insult. Pitres referred to Ribot's work [6] that asserted that the more newly acquired language deteriorates earlier than the old.

Subsequently, numerous neurologists contrasted the so-called Pitres' rule (recovery of the most familiar language) with Ribot's law (recovery of the native language), but no general rule on language recovery in bilingual aphasics has emerged. Typically, auditory and reading comprehension improve almost simultaneously in both languages, but oral language production and writing abilities improve preferentially for the treated language. Empirical studies have failed to reconcile the parallel recovery in many reported bilingual aphasiacs and the differential recovery in others. In rehabilitation, it is established that treatment confined to one language is accompanied by improvement both in that language (L1) and in the other language (L2); the choice is often left to the patient.

Recent work has emphasised the right-hemispherebased pragmatic component [19] of verbal communicative competence, the activation threshold, the control of resources and emotion in acquiring a second language (L2). These have led to the suggestion that unilinguals are at one end of a spectrum with multilinguals. No function is available to the bilingual speaker that is not already available to the unilingual, unidialectal speaker. The only difference seems to be the degree of use the speaker makes of each of the relevant cerebral systems. 


\section{Conclusions}

These diverse and at times conflicting observations imply that in certain patients impairment or recovery is differential, and in others it is parallel. Clearly further studies are needed to define mechanisms associated with differential effects: types of aphasia, size and site of the lesion, aetiology, educational level, proficiency and age of language acquisition that determine the subsequent disintegration when the brain is injured. It appears that multiple languages can in some subjects be represented, at least partially, in different brain areas. However, we should always be aware of Jackson's dictum:

'To locate the damage which destroys speech and to localise speech [itself] are two different things' [20].

\section{References}

1 Kim KHS, Relkin NR, Lee KM, Hirsch J: Distinct cortical areas associated with native and second languages. Nature 1997;388:171-174.

2 Grosjean F: Individual Bilingualism. The Encyclopedia of Language and Linguistics. Oxford, Pergamon Press, 1994.

3 Gesner JAP: Sammlung von Beobachtungen aus der Arzneygelehrtheit und Naturkunde. Nördlingen, CG Beck, 1769-1776. Cited by Roux FE, Trémoulet M (ref 14).

4 Lordat J: Analyse de la parole pour servir à la théorie de divers cas d'alalie et de parlalie. J Soc Méd Prat (Montpellier) 1843; 7:333-353, 417-433.

5 Pitres A: Etude sur l'aphasie chez les polyglottes. Rev Med 1895;15:873-899. Transl in M Paradis (ed): Readings on Aphasia in Bilinguals and Polyglots. Montreal, Marcel-Didier, 1983, pp 26-49.

6 Ribot TA: Diseases of Memory: An Essay in the Positive Psychology. New York, Appleton, 1882.
7 Warrington EK: Studies of retrograde memory: a long-term view. Proc Natl Acad Sci USA 1996;93:13523-13526.

8 Paradis M: Bilingualism and aphasia; in Whitaker H, Whitaker HA (eds): Studies in Neurolinguistics. New York, Academic Press, 1977, vol 3, pp 65-121.

-9 Fabbro F: The bilingual brain: bilingual aphasia. Brain Lang 2001;79:201-210.

10 Fabbro F: The bilingual brain: cerebral representation of languages. Brain Lang 2001;79: 211-222.

11 Klein D, Milner B, Zatorre RJ, Zhao V, Nikelski J: Cerebral organization in bilinguals: a PET study of Chinese-English verb generation. Neuroreport 1999;10:2841-2846.

12 Paradis M: Aspects of Bilingual Aphasia. Oxford, Pergamon Press, 1995.

13 Green DW: The neurocognition of recovery patterns in bilingual aphasics; in Kroll JF, de Groot AMB (eds): Handbook of Bilingualism: Psycholinguistic Perspectives. Oxford, Oxford University Press, 2005.

14 Roux FE, Trémoulet M: Organization of language areas in bilingual patients: a cortical stimulation study. J Neurosurg 2002;97:857864.
15 Lucas TH, McKhann GM, Ojemann GA: Functional separation of languages in the bilingual brain. J Neurosurg 2004;101:449-457.

-16 Aglioti S, Beltramello A, Girardi F, Fabbro F: Neurolinguistic and follow-up study of an unusual pattern of recovery from bilingual subcortical aphasia. Brain 1996;119(Pt 5):15511564.

17 Chee MWL, Tan EWL, Thiel T: Mandarin and English single word processing studied with functional magnetic resonance imaging. J Neurosci 1999; 19:3050-3056.

18 Price CJ, Green DW, von Studnitz R: A functional imaging study of translation and language switching. Brain 1999;122:2221-2235.

19 Paradis M: Generalizable outcomes of bilingual aphasia research. Folia Phoniatr Logop 2000;52:54-64.

20 Jackson JH, cited by Head H: Aphasia and Kindred Disorders of Speech. Cambridge, Cambridge University Press, 1926, p 50. 